\title{
1 Diversity in UV sensitivity and recovery potential among bacterioneuston and bacterioplankton isolates
}

\author{
A.L. Santos, S. Lopes, I. Baptista, I. Henriques, N.C.M. Gomes, A. Almeida, A. Correia and Â. Cunha \\ Center for Environmental and Marine Studies (CESAM) and Department of Biology, University of Aveiro, Campus de Santiago, Aveiro, Portugal
}

\section{Keywords}

activity, bacterioneuston, bacterioplankton, culturability, UV radiation.

\section{Correspondence \\ Ângela Cunha, Center for Environmental and Marine Studies (CESAM) and Department of Biology, University of Aveiro, Campus de Santiago, 3810-193 Aveiro, Portugal. \\ E-mail: acunha@ua.pt}

2010/1820: received 11 October 2010, revised 7 January 2011 and accepted 12 January 2011

doi:10.1111/j.1472-765X.2011.03011.x

\begin{abstract}
Aims: To assess the variability in UV-B $(280-320 \mathrm{~nm})$ sensitivity of selected bacterial isolates from the surface microlayer and underlying water of the Ria de Aveiro (Portugal) estuary and their ability to recover from previous UVinduced stress.

Methods and Results: Bacterial suspensions were exposed to UV-B radiation $\left(3 \cdot 3 \mathrm{~W} \mathrm{~m}^{-2}\right)$. Effects on culturability and activity were assessed from colony counts and ${ }^{3} \mathrm{H}$-leucine incorporation rates, respectively. Among the tested isolates, wide variability in UV-B-induced inhibition of culturability $(37 \cdot 4-99 \cdot 3 \%)$ and activity (36.0-98.0\%) was observed. Incubation of UV-B-irradiated suspensions under reactivating regimes (UV-A, $3.65 \mathrm{~W} \mathrm{~m}^{-2}$; photosynthetic reactive radiation, $40 \mathrm{~W} \mathrm{~m}^{-2}$; dark) also revealed diversity in the extent of recovery from UV-B stress. Trends of enhanced resistance of culturability (up to 15.0\%) and enhanced recovery in activity (up to $52.0 \%$ ) were observed in bacterioneuston isolates.

Conclusions: Bacterioneuston isolates were less sensitive and recovered more rapidly from UV-B stress than bacterioplankton isolates, showing enhanced reduction in their metabolism during the irradiation period and decreased culturability during the recovery process compared to bacterioplankton.

Significance and Impact of the Study: UV exposure can affect the diversity and activity of microbial communities by selecting UV-resistant strains and alter their metabolic activity towards protective strategies.
\end{abstract}

\section{Introduction}

Since the discovery of the stratospheric ozone hole, concerns regarding the ecological consequences of UV radiation have extensively increased (Häder et al. 2007). In the face of a changing global environment, the assessment of the toxic nature of UV radiation, most notably in the UV-B wavelength $(280-320 \mathrm{~nm})$ that is expected to increase as a result of the interaction of changes in UV-B fluxes resulting from ozone depletion and other climate changes (UNEP 2010), has gained pertinence.

Bacteria play a key role in nutrient cycling in aquatic ecosystems (Azam and Malfatti 2007), but their small size, short generation times and the fact that their genome comprehends a large portion of the cell volume, might make them more susceptible to the effects of UV radiation than higher organisms (Garcia-Pichel 1994).
The main biological effect of UV-B results from UVinduced formation of covalent links between adjacent pyrimidine residues, usually known as cyclobutane pyrimidine dimers. These dimers cannot be replicated and are lethal to the cell, unless damage is repaired (Mitchell and Karentz 1993). In response to UV-induced damage, bacteria have evolved several repair mechanisms that can basically be divided in dark repair and photoreactivation, a light-dependent repair mechanism that uses the photolyase enzyme, activated by UV-A (320-400 nm) and photosynthetic reactive radiation (PAR, 400-700 nm) (Walker 1984).

Located at the air-water interface, the surface microlayer (SML) represents a stressful environment for microorganisms, where pollutants and heavy metals accumulate because of its lipophilic nature, and the intensity of solar UV radiation is at its highest (Maki 1993). Adding to

\begin{tabular}{|l|l|l|l|l|l|l|l|l|l|l|l|l|}
\hline & $\mathbf{L}$ & A & M & & 3 & 0 & 1 & 1 \\
\hline
\end{tabular}


their individual effects, pollutants and UV radiation can also act additively or synergistically on aquatic microbes (Pelletier et al. 2006), through the generation of photooxidative products that might impose an additional stress on bacterioneuston, i.e. bacteria inhabiting the SML. Reports of higher bacterial abundance and activities at the SML (Kuznetsova and Lee 2001) have suggested enhanced resistance of bacterioneuston to stress, most notably UV related. However, such a trend has not yet been demonstrated, and recent work has indicated similar UV resistance in bacterial isolates from the SML and underlying water (UW) (Agogué et al. 2005), although the authors only monitored the optic density of the cultures after the irradiation period. To our knowledge, information on the variability of the responses of bacterioneuston isolates in terms of culturability and activity, as well as their repair potential under different reactivating regimes following UV exposure, is virtually inexistent.

The aim of this work was the characterization and comparative analysis of the sensitivity of bacterial isolates from the SML and UW of the estuarine system Ria de Aveiro (Portugal) and the assessment of their repair potential under different light regimes after UV-B exposure. The variability in the extent of UV-induced inactivation and the influence of different light regimes on the recovery of selected marine bacterial isolates following UV-B stress were determined in laboratory experiments using artificial radiation.

\section{Materials and methods}

\section{Sampling and isolation of marine bacterial strains}

Bacterial strains were isolated from the SML and UW of the estuarine system Ria de Aveiro, located in the western coast of Portugal. Samples from the SML were collected using a glass plate sampler (Harvey and Burzell 1972). Samples from UWs were collected by submerging a polycarbonate bottle and opening it at a depth of $0.5 \mathrm{~m}$. For the isolation of UV-resistant bacteria from the SML and UW, samples from both water layers were exposed to 2 UV-B doses between 0 and $2200 \mathrm{~J} \mathrm{~m}^{-2}$ (Philips UV-B TL $100 \mathrm{~W} / 01$ lamp, maximum emission peak at $311 \mathrm{~nm}$; intensity of $3.3 \mathrm{~W} \mathrm{~m}^{-2}$ ), with agitation $\left(50 \mathrm{rev} \mathrm{min}^{-1}\right)$ and at $c .20^{\circ} \mathrm{C}$, as described by Fernández Zenoff et al. 3 (2006a). Sample aliquots $(100 \mu \mathrm{l})$ were removed at predetermined intervals and plated in marine agar 2216 plates (MA 2216; Difco, Detroit, MI, USA). After incubation in the dark at $20^{\circ} \mathrm{C}$ for $7-14$ days, isolates were selected from the plates according to morphological differences and purified. Molecular typing of the isolates was performed by BOX-PCR, according to the procedure described by Rademaker et al. (1998), and isolates dis- playing distinct BOX profiles were identified by sequencing the 16S rRNA gene using the primer $27 \mathrm{~F}$ and an $\mathrm{ABI}$ PRISM_BigDye_Terminator Cycle Sequencing Ready Reaction kit (PE Applied Biosystems, Foster City, CA, USA). Sequences were compared with sequences available in the GenBank database by using the Basic Local Alignment Search Tool (BLAST) service to determine their approximate phylogenetic affiliations (Altschul et al. 1990). The sequences obtained were deposited in the 4 GenBank database (see Table 1 for accession numbers).

\section{Preparation of cell suspensions and irradiation condi-} tions

Bacterial isolates growing in marine broth were harvested during the exponential phase by centrifugation $(3200 \mathrm{~g}$, $15 \mathrm{~min}$ ), and the pellet was washed three times with filtered-sterilized autoclaved sea water to remove all traces of the culture medium. Cells were resuspended in filtered-sterilized autoclaved sea water, and bacterial abundance was adjusted to $10^{6}$ cells per $\mathrm{ml}$, as determined by epifluorescent microscopy counts. Bacterial suspensions were transferred to sterile plates (Corning Science Products, Corning, NY, USA) without the lid and irradiated under the UV-B source used for the initial isolation for $20 \mathrm{~min}$ (corresponding to a final UV-B dose of $3.931 \mathrm{~kJ} \mathrm{~m}^{-2}$ ). During irradiation, samples were kept at c. $20^{\circ} \mathrm{C}$ and incubated under slow shaking $\left(50 \mathrm{rev} \mathrm{min}^{-1}\right)$. All experiments were conducted in the absence of ambient light to minimize photoreactivation. After irradiation, appropriate dilutions were plated on marine agar (MA 2216). Each experiment was conducted with triplicate replicates in four independent times.

\section{Repair potential}

To determine the repair properties of the bacteria, UVB-irradiated cell suspensions were subjected to three different treatments: (i) photoreactivation with PAR, provided by white cool lamps $\left(13.44 \mathrm{~W} \mathrm{~m}^{-2} \mathrm{~s}^{-1}\right.$; Philips TLD $58 \mathrm{~W} /$ 84), (ii) UV-A provided by Philips TL $100 \mathrm{~W} / 10 \mathrm{R}$ lamps (wavelength range 350-400 $\mathrm{nm}$; intensity $3.65 \mathrm{~W} \mathrm{~m}^{-2}$ ) and (iii) darkness, by incubating the suspensions in the dark. Aliquots of samples were collected before and after incubation of the cells for 60 and $180 \mathrm{~min}$ under the different recovery regimes for culturable counts and bacterial activity assessment. Each experiment was conducted with triplicate replicates in four independent times.

\section{Culturable counts}

The UV-inactivation kinetics was followed by collecting triplicate $100-\mu \mathrm{l}$ aliquots at predetermined intervals. 
Table 1 Origin, phylogenetic affiliation, sequence similarity to the closest relative and NCBI accession number of the UV-resistant bacterial isolates used in this study

\begin{tabular}{|c|c|c|c|c|c|}
\hline Origin & Strain & Bacterial group & Closest relative (accession no.) & $\begin{array}{l}\% \text { Sequence } \\
\text { similarity }\end{array}$ & Accession no.* \\
\hline \multirow[t]{5}{*}{ SML } & Pseudomonas sp. strain NT5I1.2B & $\gamma$-Proteobacteria & Pseudomonas sp. DSM 8628 (FM208263.1) & 97 & GU084169 \\
\hline & Paracoccus sp. strain NT25I3.1A & $\alpha$-Proteobacteria & Paracoccus sp. JAM-AL07 (AB526330.1) & 99 & GQ365195 \\
\hline & Staphylococcus sp. strain NT25I2.1 & Firmicutes & $\begin{array}{l}\text { Staphylococcus saprophyticus ATCC } 15305 \\
\text { (D83371.2) }\end{array}$ & 99 & GQ365197 \\
\hline & Micrococcus sp. strain NT25I3.2AA & Actinobacteria & Micrococcus sp. TA014 (EU308453.1) & 98 & GQ365196 \\
\hline & Sphingomonas sp. NT15I1.2B & $\alpha$-Proteobacteria & Sphingomonas sp. PA225 (AM900788.1) & 100 & GU084171 \\
\hline \multirow[t]{4}{*}{ UW } & Brevibacterium sp. strain PT5I3.3L & Actinobacteria & Brevibacterium casei TSWCW1 (GQ284451.1) & 99 & GQ365205 \\
\hline & Bacillus sp. strain PT1513.2CB & Firmicutes & Bacillus cereus 5YW6 (GU991861.1) & 99 & GQ365209 \\
\hline & Acinetobacter sp. strain PT5I1.2G & $\gamma$-Proteobacteria & Acinetobacter sp. BS8Y (EU545154.1) & 97 & GQ365202 \\
\hline & Psychrobacter sp. strain PT15I3.2CA & $\gamma$-Proteobacteria & Psychrobacter piscidermidis P4-4 (EU127295.1) & 99 & GQ365208 \\
\hline
\end{tabular}

SML, surface microlayer; UW, underlying water.

*Accession numbers based on 165 rRNA partial gene sequence.

Aliquots were serially diluted in aged $0 \cdot 2-\mu \mathrm{m}$-filtered autoclaved sea water and plated in Marine agar 2216 plates. Colonies were counted after 2-7 days of incubation in the dark at $20^{\circ} \mathrm{C}$. The fraction of surviving cells was calculated by dividing the number of $\mathrm{CFU}$ in the treated sample by the number of CFU in the unirradiated sample at time zero. The dilution and plating procedures were carried out under low-luminosity conditions to avoid photoreactivation.

\section{Bacterial activity}

The bacterial activity of cell suspensions before irradiation, after irradiation and after reactivation was assessed from the rates of protein synthesis estimated by the incor5 poration of $\left[{ }^{3} \mathrm{H}\right]$ leucine (Amersham; specific activity $63.0 \mathrm{Ci} \mathrm{mmol}^{-1}$ ) into bacterial protein at $480 \mathrm{nmol} \mathrm{l}^{-1}$ final concentration in triplicate aliquots $(1.5 \mathrm{ml})$ and one trichloracetic acid (TCA; Sigma, St Louis, MO, USA) fixed blank ( $2 \%$ final concentration). After $1 \mathrm{~h}$ of incubation in the dark, proteins were precipitated by the addition of $20 \%$ TCA and samples were centrifuged. TCA-washed pellets were resuspended in $1.5 \mathrm{ml}$ of Uni-

6 versol liquid scintillation cocktail (ICN Biomedicals, USA). The radioactivity incorporated into bacterial cells was counted in a Packard Tri-Carb 2000 Liquid Scintilla-

7 tion Counter using the external standard ratio technique (Simon and Azam 1989).

\section{Results}

In this study, UV-resistant strains isolated after irradiation of samples from the SML and UW were used to assess the variability in UV-B sensitivity and recovery potential in bacterioneuston and bacterioplankton iso- lates. UV-B-induced inhibition of culturability ranged from $37 \cdot 4 \%$ in Micrococcus sp. (NT25I3.2AA) (Fig. 1a) to 99.3\% in Staphylococcus sp. (NT25I2.1) (Fig. 1e). The reduction imposed by UV-B exposure on bacterial activity ranged from $36.0 \%$ in Staphylococcus sp. (NT25I2.1) (Fig. 1e) to $98 \cdot 0 \%$ in Bacillus sp. (PT15I3.2CB) (Fig. 2b). On average, UV-B-induced reduction in bacterial culturability was up to $15 \%$ higher in bacterioplankton isolates, while the reduction in the activity was up to $25 \%$ higher in bacterioneuston isolates (ANOvA, $P<0.05$ ) (Figs 1 and 2).

Recovery of culturability under the UV-A (up to $36 \cdot 4 \%$ ) and PAR (up to $27 \cdot 6 \%$ ) regimes was observed for eight of nine of the isolates tested (Figs 1 and 2). Recovery in bacterial culturability (up to $29 \cdot 1 \%$ ) was also observed under the dark regime for six of the nine isolates tested (Figs 1 and 2). The bacterioneuston isolate Micrococcus sp. strain NT25I3.2AA (Fig. 1a) showed the highest recovery efficiency (up to $36.4 \%$ ) under all regimes tested. In general, significant differences between the patterns of recovery under the different light regimes were not detected. However, when considering the SML and UW in separate, differences emerged. For SML isolates, the most favourable light regime for the recovery of bacterial culturability was UV-A (average recovery of $11 \cdot 4 \%)$, while PAR induced the lowest recovery rate $(6 \cdot 4 \%)$. For bacterioplankton isolates, PAR led to the highest recovery rates $(9.5 \%)$, while the lowest recovery was observed under UV-A irradiation (4.6\%).

Bacterial activity also recovered, at variable extensions under the different light regimes (Figs 1 and 2). In general, UV-A radiation was the most favourable light regime in the recovery of bacterial activity (up to $78.4 \%$ ), while significant differences between recovery under PAR (up to $14 \cdot 6 \%$ ) and in the dark (up to $17 \cdot 2 \%$ ) were not found 

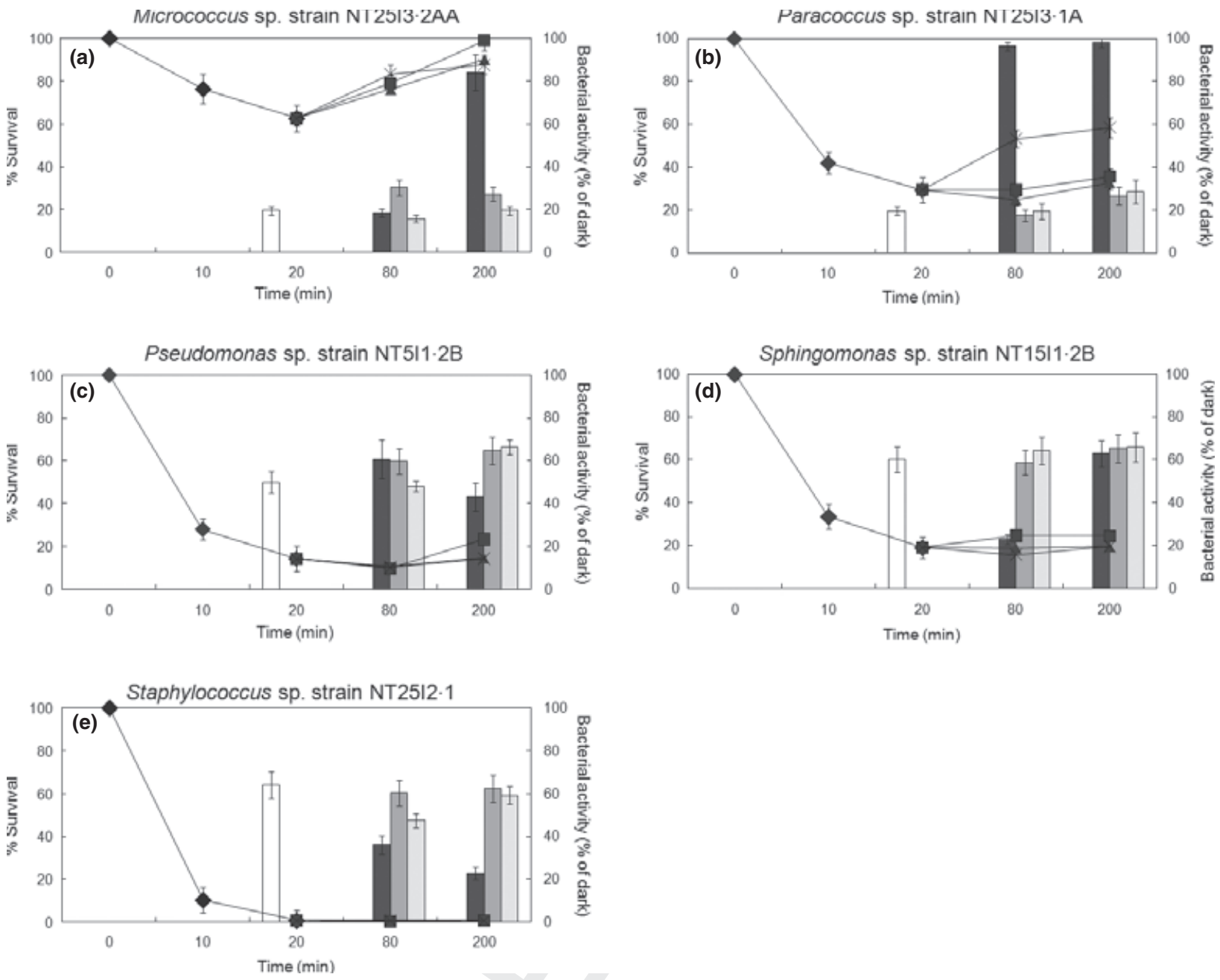

Figure 1 Effects of UV-B radiation and reactivation under different light regimes on the culturability and activity of UV-resistant bacterioneuston 14 isolates. Cells were exposed to UV-B radiation for $20 \mathrm{~min}$ and allowed to recover under different reactivation regimes (UV-A, PAR, dark) for $180 \mathrm{~min}$. Aliquots were collected after $60 \mathrm{~min}$ and $180 \mathrm{~min}$ of recovery for cultivation and activity measurements. Curves and bars in the figures correspond to the variation in culturability and activity rates, respectively. Error bars represent standard deviations of triplicate replicates of four independent experiments. Absence of error bars indicates standard deviations are too small to see on the scale used. Results are expressed as \% of the unirradiated sample at time zero. $(\square)$ UV-B; $(\square)$ UV-A; $(\square)$ PAR; $(\square)$ dark; $(-\bullet)$ UV-B; $(\rightarrow-)$ UV-A; $(\rightarrow-)$ PAR and $(\rightarrow-)$ dark. PAR, photosynthetic reactive radiation.

$(P>0 \cdot 05$, one-way ANova $)$. Bacterioneuston isolates Paracoccus sp. strain NT25I3.1A (78.4\%) (Fig. 1b) and Pseudomonas sp. strain NT5I1.2B (14.6\%) (Fig. 1c) showed the highest recovery rates in bacterial activity under the UV-A and PAR regime, while the planktonic isolate Bacillus sp. strain PT15I3.2CB (17.2\%) (Fig. 2b) recovered the most under the dark regime. When considering the compartment from which the bacterial isolates were retrieved, the patterns observed for bacterial culturability were maintained; though for bacterioplankton isolates, significant differences were observed in the extent of the recovery in the dark and under UV-A radiation (twice as high than under the dark regime).

\section{Discussion}

Several studies on UV sensitivity and recovery potential in bacteria from diverse aquatic environments have been conducted (Joux et al. 1999; Arrieta et al. 2000; Agogué et al. 2005). However, to our knowledge, no information exists on the diversity of the UV responses of bacterioneuston isolates in terms of culturability, activity and recovery from previous UV-induced stress. Therefore, in this study, the variability in the UV sensitivity and recovery potential of selected UV-resistant bacterioneuston and bacterioplankton isolates was assessed under standardized experimental conditions using a number of isolates simi- 

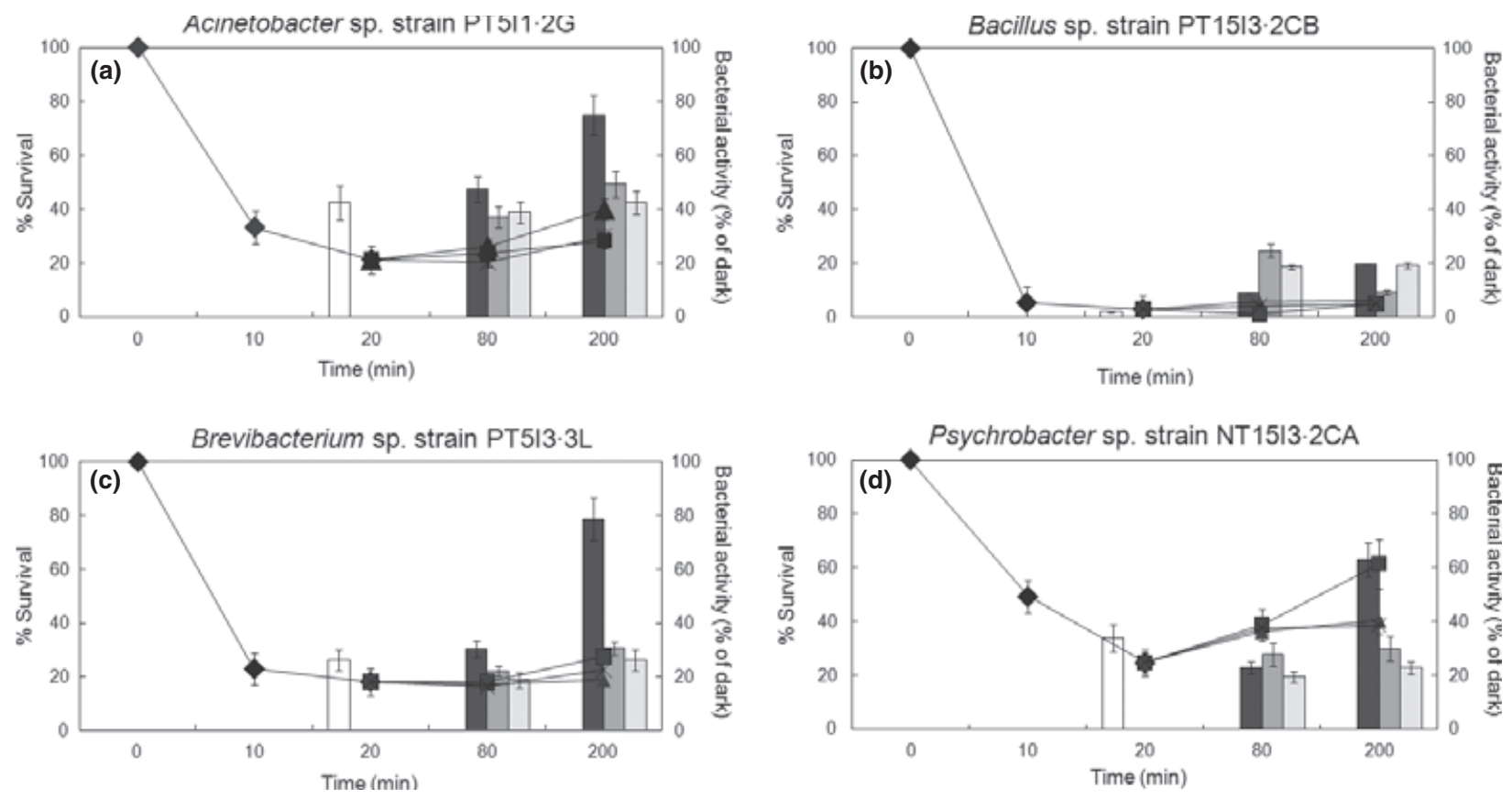

Figure 2 Effects of UV-B radiation and reactivation under different light regimes on the culturability and activity of UV-resistant bacterioplankton $\mathbf{1 5}$ isolates. Cells were exposed to UV-B radiation for $20 \mathrm{~min}$ and allowed to recover under different reactivation regimes (UV-A, PAR, dark) for $180 \mathrm{~min}$. Aliquots were collected after $60 \mathrm{~min}$ and $180 \mathrm{~min}$ of recovery for cultivation and activity measurements. Curves and bars in the figures correspond to the variation in culturability and activity rates, respectively. Error bars represent standard deviations of triplicate replicates of four independent experiments. Absence of error bars indicates standard deviations are too small to see on the scale used. Results are expressed as \% of the unirradiated sample at time zero. ( $\square$ ) UV-B; $(\square)$ UV-A; $\square$ PAR; $(\square)$ dark; $(\bullet)$ UV-B; $(--)$ UV-A; $(\bullet)$ PAR and $(\rightarrow-)$ dark. PAR, photosynthetic reactive radiation.

lar to previous studies (Joux et al. 1999; Arrieta et al. 2000; Fernández Zenoff et al. 2006b).

Exposure to UV-B radiation revealed considerable variability in sensitivity to UV stress among the tested isolates, in agreement with previous reports (e.g. Arrieta et al. 2000; Ordoñez et al. 2009). Micrococcus sp. (NT25I3.2AA) showed the smallest reduction in culturability upon UV-B exposure. High UV resistance of several Micrococcus strains isolated from other UV-exposed environments is well documented in the literature (e.g. Fern-

8 ández Zenoff et al. 2006a,b; Ordoñez et al. 2009). The characteristically high $\mathrm{G}+\mathrm{C}$ content of Actinobacteria has been proposed to confer a protective effect against UV radiation, by protecting DNA against damage by thymidine dimerization (Singer and Ames 1970). However, recent work (Matallana-Surget et al. 2008) has suggested that micro-organisms with high GC content could, in fact, be more prone to UV-induced mutations, because cytosine-containing photoproducts are highly mutagenic. The determinants of UV resistance in Micrococcus sp. remain, therefore, unknown.

Considerable differences were also observed in the extent of UV-induced inhibition of bacterial activity. The observation that Staphylococcus sp. (NT25I2.1) was the strain most inhibited in terms of culturability but less inhibited in terms of activity is intriguing, as one would expect the two biological parameters to be correlated. A similar trend was also observed in Micrococcus sp. (NT25I3.2AA) that was least affected in terms of culturability but was the second most affected strain in terms of activity ( $80 \cdot 4 \%$ inhibition). A possible explanation would be the induction of a metabolic shift from growth (protein synthesis) to survival upon UV-B exposure, recently proposed to occur in Bacillus cereus in response to acid stress (Mols et al. 2010). Further studies are needed to reveal whether such a response also occurs upon UV-B stress.

The most important biological effects of UV-B radiation are probably a consequence of the stalling of replication fork complexes by UV-B-induced DNA lesions that block replisome movement or synthesis by the polymerase subunits. Therefore, the ability of bacteria to survive UV$\mathrm{B}$ radiation is closely related to their ability to either bypass or correct such damaged DNA segments (Friedberg 1985).

Following UV-B exposure, the recovery potential of the bacterial isolates was assessed under different light regimes. UV-A and PAR were the most effective regimes 
in the recovery of culturability, but recovery under the dark regime was also observed for most isolates. Such observation demonstrates the importance of photoreactivation, and particularly the enzyme photolyase, in the recovery from UV-B stress, in accordance with previous studies (e.g. Kaiser and Herndl 1997). The importance of photoreactivation for bacterial communities might be related to its extreme efficiency, splitting approximately one dimer for every blue-light photon absorbed. Furthermore, unlike dark repair, photoreactivation does not require energy mobilization and may be particularly important in nutrient-limited aquatic microbial populations (Joux et al. 1999). Recovery in terms of bacterial activity was also observed under the different light regimes, demonstrating that UV-induced impairment of biological functions was not irreversible being, in general, UV-A the most effective light regime for activity recovery.

Although the number of isolates used in this study is too small to attempt the establishment of a correlation between the origin of the isolates and their UV sensitivity, some trends were in fact identified. For example, UVinduced reductions in bacterial culturability were up to $15 \%$ lower in bacterioneuston, suggesting the presence of bacteria displaying enhanced resistance to UV radiation at the SML. The average recovery in terms of culturability was generally higher in bacterioplankton isolates (up to $33.5 \%)$ than in bacterioneuston for all light regimes. On the other hand, in terms of activity, the recovery was higher in bacterioneuston (up to $52.0 \%$ ) under all the reactivating conditions tested. The observation of enhanced recovery in activity accompanied by reduced recovery in culturability in bacterioneuston isolates could indicate the engagement in a viable but nonculturable condition as a stress response and/or defence mechanism that allows for the rapid re-establishment of bacterial activity when UV exposure is terminated. This hypothesis is supported by the observation that the UV-induced decrease in total cell numbers, determined by epifluorescence microscopy counts of acridine orange-stained preparations, was much lower than the one of CFU numbers (data not shown). Such a strategy has been reported, for example, in species of the genus Vibrio sp. upon exposure to thermal, saline and acidic stress (Wong and Wang 2004).

While addressing the resistance of bacterioneuston and bacterioplankton strains to solar UV radiation, by directly isolating culturable bacteria from the SML and UWs and monitoring the optic density of the irradiated cells, Agogué et al. (2005) concluded that UV resistance was similarly distributed in bacterioneuston and bacterioplankton. Alternatively, in this study, samples from the SML and UW were exposed to UV-B radiation and resistant bacteria were isolated (Fernández Zenoff et al. (2006a)). This approach may offer a more realistic perspective on bacterial UV resistance in a context of increased UV-B levels (UNEP, 2010), because the strains retrieved represent the dominant members of the culturable fraction of bacterioneuston and bacterioplankton challenged with elevated UV-B radiation, and the metabolic strategies they adopt to cope with this stress may modulate the overall functioning of the communities exposed to heighted UV-B doses.

The differences in the UV sensitivity of bacteria inhabiting the SML and UW that seem to emerge by the selective elimination of sensitive phenotypes and the enrichment in resistant strains can indicate the presence of UV-resistant members in the bacterioneuston population.

\section{Acknowledgements}

Acknowledgments are due to the anonymous reviewers that greatly improved the earlier version of this manuscript. Financial support for this work was provided by CESAM (Centre for Environmental and Marine Studies, University of Aveiro) and by the Portuguese Foundation for Science and Technology (FCT) in the form of a PhD grant to A.L. Santos (SFR/BD/40160/2007) and a postDoctoral grant to I. Henriques (SFRH/BPD/21384/2005).

\section{References}

Aertsen, A. and Michiels, C.W. (2004) Stress and how bacteria cope with death and survival. Crit Rev Microbiol 30, 263273.

Agogué, H., Joux, F., Obernosterer, I. and Lebaron, P. (2005) Resistance of marine bacterioneuston to solar radiation. Appl Environ Microbiol 71, 5282-5289.

Arrieta, J.M., Weinbauer, M.G. and Herndl, G. (2000) Interspecific variability in sensitivity to UV radiation and subsequent recovery in selected isolates of marine bacteria. Appl Environ Microbiol 66, 1468-1473.

Azam, F. and Malfatti, F. (2007) Microbial structuring of marine ecosystems. Nat Rev Microbiol 5, 782-791.

Fernández Zenoff, V., Heredia, J., Ferrero, M.A., Siñeriz, F. and Farías, M.E. (2006a) Isolation of UV resistant bacteria from high altitude Andean wetland bacterial community. Curr Microbiol 52, 359-362.

Fernández Zenoff, V., Siñeriz, F. and Farías, M.E. (2006b) Diverse responses to UV-B radiation and repair mechanisms of bacteria isolated from high-altitude aquatic environments. Appl Environ Microbiol 72, 7857-7863.

Friedberg, E.C. (1985) DNA Repair, p. 614. NY: W. H. Freeman and Company.

Garcia-Pichel, F. (1994) A model for internal self-shading in planktonic organisms and its implications for the useful- 
ness of ultraviolet sunscreen. Limnol Oceanogr 39, 1704 1717.

Häder, D.P., Kumar, H.D., Smith, R.C. and Worrest, R.C. (2007) Effects of solar UV radiation on aquatic ecosystems and interactions with climate change. Photochem Photobiol Sci 6, 267-285.

Harvey, G.W. and Burzell, L.A. (1972) A simple microlayer method for small samples. Limnol Oceanogr 17, 156-157.

Joux, F., Jeffrey, W.H., Lebaron, P. and Mitchell, D.L. (1999) Marine bacterial isolates display diverse responses to UV-B radiation. Appl Environ Microbiol 65, 3820-3827.

Kaiser, E. and Herndl, G.J. (1997) Rapid recovery of marine bacterioplankton activity after inhibition by radiation in coastal waters. Appl Environ Microbiol 63, 4026-4031.

Kuznetsova, M. and Lee, C. (2001) Enhanced extracellular enzymatic peptide hydrolysis in the sea-surface microlayer. Mar Chem 73, 319-332.

Maki, J.S. (1993) The air-water interface as an extreme environment. In Aquatic Microbiology - An Ecological Approach ed. Ford, T.E. pp. 2133-2144. Boston, MA: Blackwell Scientific.

Matallana-Surget, S., Meador, J.A., Joux, F. and Douki, T. (2008) Effect of the GC content of DNA on the distribution of UVB-induced bipyrimidine photoproducts. Photochem Photobiol Sci 7, 794-801.

Mitchell, D.L. and Karentz, D. (1993) The induction and repair of DNA photodamage in the environment. In Environmental UV Photobiology ed. Young, A.R., Bjorn, L.O.,

11 Moan, J. and Nultsch, W. pp. 345-377. NY: Plenum Press. Mols, M., van Kranenburg, R., van Mells, C.C.J., Moezelaar, R. and Abee, T. (2010) Analysis of acid-stressed Bacillus cereus reveals a major oxidative response and inactivationassociated radical formation. Environ Microbiol 12, 873885.

Ordoñez, O.F., Flores, M.R., Dib, J.R., Paz, A. and Farias, M.E. (2009) Extremophile culture collection from Andean lakes: extreme pristine environments that host a wide diversity of microorganisms with tolerance to UV radiation. Microb Ecol 58, 461-473.

Pelletier, E., Sargian, P., Payet, J. and Demers, S. (2006) Ecotoxicological effects of combined UVB and organic contaminants in coastal waters: a review. Photochem Photobiol 82, 981-993.

Rademaker, J.L.W., Louws, F.J. and de Bruijn, F.J. (1998) Characterization of the diversity of ecologically important microbes by rep-PCR genomic fingerprinting. In Molecular Microbial Ecology Manual, supplement 3 ed. Akkermans, A.D.L., van Elsas, J.D. and de Bruijn, F.J. pp. 1-26. Dordrecht: Kluwer.

Simon, M. and Azam, F. (1989) Protein content and protein synthesis rates of planktonic marine bacteria. Mar Ecol Prog Ser 51, 201-213.

Simonson, C.S., Kokjohn, T.A. and Miller, R.V. (1990) Inducible UV repair potential of Pseudomonas aeruginosa PAO. J Gen Microbiol 136, 1241-1249.

Singer, C.E. and Ames, B.N. (1970) Sunlight ultraviolet and bacterial DNA base ratios. Science 170, 822-826.

UNEP (2010) Environmental effects of ozone depletion and its interactions with climate change: progress report, 2009. Photochem Photobiol Sci 9, 275-294.

Walker, G.C. (1984) Mutagenesis and inducible responses to deoxyribonucleic acid damage in Escherichia coli. Microbiol Rev 48, 60-93.

Weigand, M.R. and Sundin, G.W. (2009) Long-term effects of inducible mutagenic DNA repair on relative fitness and phenotypic diversification in Pseudomonas cichorii 302959. Genetics 181, 199-208.

Wong, H.C. and Wang, P. (2004) Induction of viable but nonculturable state in Vibrio parahaemolyticus and its susceptibility to environmental stresses. J Appl Microbiol 96, 359366. 